\title{
The CDS and the Government Bonds Markets During the Last Financial Crisis
}

\author{
France Križanič ${ }^{*}$ \\ Žan Jan Oplotnik**
}

\begin{abstract}
Financial market had developed a special instrument to insure the buyers of bonds. This instrument is so called Credit Default Swap (CDS). The CDS price is a kind of insurance premium that the buyer of CDS pays to the seller of CDS in exchange for compensation of possible loss in operation. Paper analyses causality between CDS price and dynamics of bond yields and influence of macroeconomic factors on it in four selected countries during the last financial crisis. Analysis results show that there is no important macroeconomic variable included in the analysis that preceded the CDS prices connected with German government bonds. Sellers of CDS were apparently aware of the systemic nature of the financial crisis in the euro area. In the case of the United Kingdom, Russia and Slovenia we can observe the unemployment rate as the most important macroeconomic variable that preceded the CDS prices for government bonds.
\end{abstract}

Keywords: Bonds, Yield, CDS, International financial markets, Macroeconomics

JEL Classification: E44; F34; G15

\section{Introduction and CDS market}

This article shows the operation of the CDS (Credit Default Swap) market, a new instrument on the financial market. It increases the security of the investment in bonds while allowing speculation, since CDS can be traded like bonds. In the article we first introduce the economic theory of the new financial instrument CDS and its specific market, then we analyze the Granger causality connection between the dynamics of the CDS prices, the government's bond yields and macroeconomic fundamentals of four countries included in our sample (the United Kingdom, Germany,

\footnotetext{
* France Križanič is at EIPF Ltd. Economic institute, Ljubljana, Slovenia.

** Žan Jan Oplotnik is at University of Maribor, Faculty of Economics and Business, Maribor, Slovenia.
} 
Russia and Slovenia). We finish the article with conclusions, an outline of the methodology, literature and data sources.

In the 1990s there was a special instrument developed on the financial markets to insure bond buyers ahead of eventual loss in their investment (Stulz, 2010). The Instrument was named Credit Default Swap (CDS) ${ }^{1}$. The CDS is a contract according to which the seller of the CDS insures the buyer of the CDS (that is, in principle, also the buyer of bonds) to replace the damage incurred in the event of bankruptcy (or default) of his debtor (that is, the issuer of the bond). In return for the insurance the seller of the CDS gets the premium expressed as a percentage of the insured bond's value. The debtor in the basic relationship ("reference unit") is the issuer of the bond. He is, however, not included in the CDS contract under which his creditor (the buyer of this bonds) bought the CDS from the economic entity (usually a financial institution) that is going to insure this credit. In case of default in the basic contract (the issuer of the bonds does not fulfill its obligation on time ${ }^{2}$ ), the seller of the CDS pays to the CDS buyer the contract value (par value) of basic obligation (defined with the bond edited in the basic contract).The CDS contract specifies exactly the method of payment that the CDS seller provides for the CDS buyer in case of a "credit event" (the issuer of the bond does not pay his matured obligation established by the bond). In doing so, the CDS seller may pay the CDS buyer the entire nominal value of the bonds (a socalled "physical settlement") or the difference between the face value and the market value of the defaulted bonds (a "cash settlement"). The value of the bonds usually does not fall to zero. Some of this value remains even after the bankruptcy of the bond's seller, and it is also quite possible that the bond's issuer completely fulfills his obligation after a certain delay (Duffie, 1999). In the case of a "credit event" occurring at a large "reference unit" (its obligations under the bond issue does not settle a larger bank or other similar institution), there are usually many CDS sellers and CDS buyers (the CDS market enables the CDS sellers to distribute the risk taken by the CDS) and debt settlement from this relationship is carried out on a special auction, named "credit-fixing event". Sometimes there are more CDS sellers that fulfill the CDS contract with just one CDS buyer. Such a contract is made on auction and is called "Loan Only Credit Default Swap" (LCDS).The difference between CDS and a real insurance relationship is in fact that the CDS is a financial market instrument that can be traded (Stulz, 2010). On the other side, a CDS is not a security. Economic entities that are buying and selling CDS often have nothing to do with the basic relationship (issue of bonds); they have just certain expectations. These may be rather strange expectations because the CDS buyer, who is not at the same time the creditor from the relationship established with the given bond, can have an economic interest in the bankruptcy of this bond's issuer ("reference unit"). In this case, his payment of the premium or the price of the CDS has an economic sense. This is similar to the position of someone who pays the insurance for a possible fire at a neighbor's house and gets paid for the amount of damage if the neighbor's house, in fact, burns. The 
relationship established with the CDS contract is such that the buyer of the CDS is, in the case of a harmful event (default from the relationship established with the bond), repaid, without receiving any damage. A CDS in which the buyer of the CDS is not at the same time the buyer of bonds is called "the naked CDS". Their advantage is that they increase the scope of the market and its liquidity and, indirectly, the ability of CDS sellers to finance activity in this area. For the bond buyers and CDS buyers, CDS are important because they reduce risk and for banks they also reduce the capital needed to insure these risks. Thus, by purchasing the CDS, commercial banks improve capital adequacy.

Buyers of CDS yet hold risk (Stulz, 2010). The first risk is that there will be no default of bonds (the risk when a CDS buyer is not at the same time also a bond buyer; it is the creditor from the basic relationship). The second risk is in the possibility that the CDS seller will not be able to pay the amount that was protected with the purchase of the CDS. Sometimes the CDS seller guarantees his obligations with his property, but it can happen that in the case of a "credit event" this property is not in liquid form. It is, therefore, also a liquidity risk. The CDS market was at first completely deregulated, but gradually regulation to this field increased. Regulators first claimed improvement in information on this market and then (2009) also on the mandatory use of clearing houses as well as the international standardization of the contracts. In 2012, the EU forbade "naked CDS" connected with the national bonds' insurance (Murdock, 2013).

The premium wanted by the CDS seller depends on his assessment of the risk taken by selling CDS. It is interesting to note the relationship between the bond's yield and the CDS premium on the same bond. The relationship between the price of CDS (the premium) and spread of the bond's yield that this CDS insures is called the "basis". It can be positive (CDS price > bond's yield) or negative (CDS price < bond's yield). A positive "basis" shows that economic subjects prefer liquidity, and that they want to, even for a high price, avoid risk (Fontana A., Scheicher M., 2010). Of note is also the difference in the changing bond's yield and CDS prices.

Investors on the CDS market are in principle more informed than the bond buyers, so we can expect that CDS prices should influence the bond's yield, and that a bond's yield changes should lag behind the changes of CDS prices (Li, Huang, 2011). For the same phenomenon, there can also be a different explanation: a speculative attack on the given issuer usually begins on the CDS market and proceeds to the bond market. But there is not, of course, any change in the prices of the CDS and the required bond's yield that are tied to the speculative attacks, which have the ultimate interests of the speculators that the debtor goes out of business or declares insolvency (Fontana A., Scheicher M., 2010). The financial crisis after September 2008 has shown that the introduction of CDS on the financial market caused its greater vulnerability. Financial institutions became more interconnected and, consequently, the systemic risk enlarged. After the introduction of CDS, a financial institution's solvency became 
more uncertain (Stulz, 2010). In this crisis some CDS sellers have not been able to settle their commitments, and some CDS buyers took on too much risk. This was the reason for straightening CDS market regulation.

\section{A connection between CDS, bond yields and macroeconomic fundamentals}

The data about prices of CDS connected to state bonds are hardly accessible. We have obtained them for Great Britain, Russia, Germany and Slovenia for the period from January 2009 to December 2012 (after the onset of the current financial crisis). The CDS prices are expressed in points. 100 points means one percentage point of the basic value, i.e. the value of the insured bond. Our sample has one large (Germany) and one small (Slovenia) economy that are both members of the Eurozone; then there is one large economy, an EU Member State not on the Euro which is a part of the Anglo-Saxon economic space (United Kingdom); and finally, there is one large economy from Eurasia (Russia). The main characteristics about CDS prices and government bonds' yields for the mentioned countries are presented in Table 1. The Granger causality test's results are presented in Table 2 (comparing the dynamics in the government bond's yield and the dynamics of CDS prices) and Table 4 (comparing the dynamics of different macroeconomic variables in the country of the bond's issuer and the dynamics of CDS prices). Table 3 presents the scheme of macroeconomic variables that should be taken into account by government bond buyers and also by the CDS sellers that insure these bonds when they settle the government bond's yields and CDS prices. Due to limited data, the results in this section can only indicate if changes in CDS prices lag behind changes of government bond's yields and vice versa, as well as if the changes in CDS prices lag behind the changes of different variables showing macroeconomic fundamentals in the given country.

We can see in Table 1 that in all four countries the CDS prices (for comparison they must be divided by 100) are smaller than the bonds' yields. We can also see two different regimes in the dynamics of CDS prices during the financial crisis. In Britain and in Russia the CDS prices reached a peak in February 2009 (at the time of the deepest recessions associated with financial crises after September 2008) and then quickly declined. The CDS prices were cut in half in the UK and had decreased by more than two-thirds in Russia. In December 2012, UK prices were the lowest among all four observed national economies- only 60 points. In Slovenia and Germany the prices of CDS increased during the analyzed period. In Germany they reached the highest level in June 2012, and in Slovenia they were the highest in August 2012. Sellers of CDS were apparently aware of the systemic nature of the financial crisis in the euro area. The data in Table 1 also indicates that the speculative attack on Slovenian bond prices (the consequence of this attack was the huge increase in the difference between Slovenian and German bonds' yields) did not take place via the CDS market. 
In December 2012 the spread between Slovenian and German bonds' yields was 4 percentage points (400 basis points), while the CDS prices connected to Slovenian government bonds was just 281 basis points (for comparison with the bond's yield, this is 2.81 percentage points). The negative base (larger spread in the bond's yield than the CDS price) shows that the players in the market regarded their investment in Slovenian bonds as safe (Fontana, Scheicher, 2010).

The results of the Granger causality assessment between growth rates in bonds' yields and growth rates of CDS prices for the countries in our sample are presented in Table 2. The test is carried out on seasonally adjusted monthly data from February 2009 to December 2012. The percentages in the third row of Table 2 show the probability that the dynamics (growth or decline) in the government bonds' yields did not change before the change in CDS prices. Conversely, the percentages in the bottom line of this table show the probability that the dynamics of CDS prices had not changed before the growth rates of bond yields. The higher the percentage (closer to $100 \%$ ), the lower is the probability that bond yield growth rates changed in the 12 months prior to the growth rates of CDS prices (third row in Table 2), whereas lower is the probability that the growth rates of CDS prices changed before the growth rates of bond's yields (fourth row in Table 2). The higher the percentage, the weaker is Granger causality. The results in Table 2 show the expected large differences in mutual dynamics of bond yields and CDS prices in the analyzed countries. In the case of the UK there is no connection in this relationship. The dynamics of the CDS prices and the government bond's yield are not ahead of each other. In Russia, interesting and contrary to expectations (Li, Huang, 2011), the dynamics of the government bond's yield precedes the dynamics of CDS prices. This suggests that the insurance relationships for bonds are formed on the base of the bond's yield changes. It means that sellers and buyers of CDS set the prices of this financial instrument depending on the bond's market circumstances. Topic was covered also by Ang, Longstaff (Ang, Longstaff, 2012). In Germany and Slovenia, countries that are exposed to the systemic risk in the euro area, there is a balanced connection between the Granger causality in the dynamics of the bond yields and the dynamics of the CDS prices. Here are obviously fluctuations where sometimes changes in CDS prices precede changes in bond's yield, and vice versa. This is an expected result of uncertainty in the market. We also estimated Granger causality between the dynamics of different macroeconomic variables that influence the changes in the government bond's yields and the dynamics of the CDS prices. Table 3 shows a schematic overview of these macroeconomic variables. The economic growth in the given national economy is presented by unemployment rate, the circumstances on the capital markets are presented by the Central Bank's interest rate and stock market index, the economic stability in given national economy is presented by retail price index and general government debt-to-GDP, while the S\&P country rating presents the confidence in the economy of this country. 
The Granger causality between the dynamics of different macroeconomic variables that influence the changes in the government bond's yields and the dynamics of the CDS prices are presented in Table 4. A high percentage (close to 100\%) shows that the growth or decline of a given macroeconomic variable is not ahead of growth or decline in the CDS prices (connected with government bond). This means that the changes of a given macroeconomic variable do not precede CDS prices. A low percentage shows the opposite. Here, Granger causality indicates that a given macroeconomic variable's changes precede the dynamics of CDS prices.

Table 1: The CDS prices - premiums (in basic points) and the bond's yield (\%)

\begin{tabular}{|c|c|c|c|c|c|c|}
\hline & & $\begin{array}{c}\text { January } \\
2009\end{array}$ & $\begin{array}{c}\text { December } \\
2012\end{array}$ & $\begin{array}{l}\text { The difference } \\
\text { (XII/2012 } \\
\text { - I/2009) }\end{array}$ & $\begin{array}{c}\text { The highest CDS price } \\
\text { and the bond's yield in } \\
\text { the same month }\end{array}$ & $\begin{array}{l}\text { The month when } \\
\text { the highest CDS } \\
\text { price was reached }\end{array}$ \\
\hline \multirow[t]{2}{*}{ Slovenia } & CDS price & 171 & 281 & 110 & 511 & August 2012 \\
\hline & Bond's yield & 4.90 & 5.36 & 0.46 & $6.99^{1}$ & - \\
\hline \multirow[t]{2}{*}{ Germany } & CDS price & 54 & 74 & 20 & 134 & June 2012 \\
\hline & Bond's yield & 3.08 & 1.36 & -1.72 & $1.43^{2}$ & - \\
\hline \multirow[t]{2}{*}{$\begin{array}{c}\text { United } \\
\text { Kingdom }\end{array}$} & CDS price & 124 & 60 & -64 & $142^{2}$ & February 2009 \\
\hline & Bond's yield & 3.60 & 1.85 & -1.75 & 3.65 & - \\
\hline \multirow[t]{2}{*}{ Russia } & CDS price & 648 & 190 & -458 & 676 & February 2009 \\
\hline & Bond's yield & 12.82 & 6.78 & -6.04 & $14.53^{1}$ & - \\
\hline
\end{tabular}

${ }^{1}$ The maximum yield was reached in the same month as the highest level of the CDS prices.

${ }^{2}$ The yield had not reached the highest level in the same month as the CDS price. They were the highest in June 2009 in Germany and in February 2010 in the UK.

Table 2: Granger causality between changes in government bond yield and adequate CDS price

\begin{tabular}{|c|c|c|c|c|}
\hline Estimated for a & Slovenia & Germany & United Kingdom & Russia \\
\hline 12 month period & & Probability & & \\
\hline $\begin{array}{c}\text { The dynamics of the bond's yield } \\
\text { is not before the dynamics of the CDS prices }\end{array}$ & $35 \%$ & $51 \%$ & $77 \%$ & $1 \%$ \\
\hline $\begin{array}{c}\text { The dynamics of the CDS prices } \\
\text { is not before the dynamics of the bond's yield }\end{array}$ & $36 \%$ & $33 \%$ & $94 \%$ & $57 \%$ \\
\hline
\end{tabular}


Table 3: A schematic overview of variables that influence the level of bond yields and the CDS prices

\begin{tabular}{|l|l|}
\hline Economic growth & Unemployment rate \\
\hline \multirow{2}{*}{ Capital market } & Central Bank's interest rate \\
\cline { 2 - 2 } & Stock market index \\
\hline \multirow{2}{*}{ Macroeconomic stability } & Retail price index \\
\cline { 2 - 2 } & general government debt-to-GDP \\
\hline Confidence & S\&P country rating \\
\hline
\end{tabular}

Table 4: Granger causality between the changes of different macroeconomic variables and CDS prices

\begin{tabular}{|c|c|c|c|c|}
\hline $\begin{array}{c}\text { Estimated for a } \\
\begin{array}{c}12 \text { month } \\
\text { period }\end{array}\end{array}$ & $\begin{array}{c}\text { Slovenia } \\
\text { variable is not }\end{array}$ & $\begin{array}{c}\text { Germany } \\
\text { before the }\end{array}$ & $\begin{array}{c}\text { United Kingdom } \\
\text { of a given } \\
\text { changes of }\end{array}$ & $\begin{array}{c}\text { macroeconomic } \\
\text { the CDS price }\end{array}$ \\
\hline Unemployment rate & $9 \%$ & $48 \%$ & $3 \%$ & $18 \%$ \\
\hline Central Bank's interest rate & $5 \%$ & $58 \%$ & -1 & $96 \%$ \\
\hline Stock market index & $37 \%$ & $97 \%$ & $93 \%$ & $11 \%$ \\
\hline Retail price index & $66 \%$ & $91 \%$ & $85 \%$ & $14 \%$ \\
\hline General government debt (\% of GDP) & $98 \%$ & $62 \%$ & $34 \%$ & $67 \%$ \\
\hline S \& P country rating & $76 \%$ & $75 \%$ & $14 \%$ & $41 \%$ \\
\hline
\end{tabular}

${ }^{1}$ The interest rate of the British Central Bank was nearly unchanged between 1/2009 and 12/2012.

The results in Table 4 show that none of the relevant German macroeconomic variables have the dynamics by which we would be able to discover Granger causality between the CDS prices connected to the government bonds from this country. These prices are likely to be under the influence of systemic risk in the Eurozone, hence the increase in the CDS prices to the German government bonds from January 2009 to December 2012. In Slovenia, the dynamics of the CDS prices were preceded by the growth or decline in the unemployment rate and the changes in ECB interest rate. According to the results, between $30 \%$ and $40 \%$ of CDS prices for Slovenian bonds are less typical, but with notable exceptions of being preceded by Slovenian stock market index dynamics. In the UK the changes in CDS prices on government bonds are markedly preceded by the dynamics of the unemployment rate, credit rating and government debt (as a share in GDP). In Russia, however, ahead of the dynamics of the CDS prices for government bonds are the changes in unemployment rate, stock market index and inflation. Taken as a whole, Granger causality is notable in taking into account the changes in the unemployment rate and changes of CDS prices for government bonds in Great Britain, Russia and Slovenia. 


\section{Conclusions}

The first and the approximate assessment of the connection between the dynamics of the government bonds' yields and the CDS prices on these bonds (Granger causality) shows that in the UK none of these variables changes precede another. In Russia this relation was shown to be in the opposite of the theoretical expectations. The dynamics of the yields on Russian government bonds precedes the dynamics of their CDS prices. In Germany and Slovenia, however, there are the fluctuations in a sense that changes in government bonds' yields first precede and later lag behind the changes in CDS prices, and vice versa. This is an expected result of uncertainty in the market. A brief evaluation of the CDS market for four countries and the period 2009-2012 shows that after the beginning of the global financial crisis the CDS prices for state bonds changed in two different regimes. Outside the Eurozone (United Kingdom and Russia) CDS prices reached a peak in February 2009 (at the time of deepest recessions associated with financial crises after September 2008) and then quickly declined. For the countries within the Eurozone (Germany and Slovenia) CDS prices for state bonds increased. Sellers of CDS were apparently aware of the systemic nature of the financial crisis in the euro area. Granger causality tests show that there is no important macroeconomic variable included in the analysis that precede the CDS prices connected with German government bonds, while in the case of the United Kingdom, Russia and Slovenia we can observe the unemployment rate as the most important macroeconomic variable that precedes the CDS prices for government bonds.

\section{About the methodology}

The Granger causality was estimated to see if the CDS prices' dynamics (growth rates of these prices) precede or lagged behind the dynamics (growth rates) of government bonds' yields in the sample of the four countries (United Kingdom, Germany, Russia and Slovenia) after the start of the world's most recent financial crisis. In a similar way we also estimated Granger causality between growth rates of different macroeconomic variables (unemployment rate, Central Bank's interest rate...) and the CDS prices growth rates. Granger causality was estimated for the period from February 2009 to December 2012 and for the allocation of time for one factor preceding the other in twelve months. Series, used in the analysis, were seasonally adjusted, and we passed the Unit Root Test.

Granger causality shows no substantive connection between two economic variables, but only the fact that changes of one economic variable precedes the changes of other. It is the first information before further econometric analysis. Granger causality (Granger, 1969) between the CDS prices' growth rates and government bonds' yields growth rates was estimated by the following equations (shown for the case of the United Kingdom): 
[b_uk / b_uk $(-1)-1)]=\mathrm{f}\left\{\mathrm{con}+\left[\mathrm{b} \_\mathrm{uk}(-1) /\right.\right.$ b_uk $\left.\left.(-2)-1\right)\right]+\ldots+$

$+[$ b_uk (-12) / b_uk (13) - 1)] $+[$ cds_uk $(-1) /$ cds_uk $(-2)-1)]+\ldots+$

$+[$ cds_uk $(-12) /$ cds_uk (13) - 1)] $+\mathrm{u}$ \}

and

$[$ cds_uk $/$ cds_uk(-1) -1$)]=\mathrm{f}\left\{\mathrm{con}+\left[\mathrm{cds} \_\mathrm{uk}(-1) / \mathrm{cds} \_\mathrm{uk}(-2)-1\right)\right]+\ldots+$

$+[$ cds_uk $(-12) /$ cds_uk $(13)-1)]+[$ b_uk $(-1) /$ b_uk $(-2)-1)]+\ldots+$

$+[$ b_uk (-12) / b_uk (13) - 1)] +u\}

Where:

con - constant;

b_uk - UK government bond's yield (in percentages), b_uk(-1) is the same variable in the previous month, ..., b_uk(-13) is the same variable 13 months ago;

cds_uk - CDS price (in the points) for UK government bonds insurance, cds_uk (-1) is the same variable in previous month, ..., cds_uk (-13) is the same variable in 13 months ago;

$\mathrm{u}-\quad$ the unexplained residuals of the dependent variable.

The hypothesis in the first equation is that there is no Granger causality between CDS price growth rates and growth rates of the government bond yield for given country (it means that the dynamics of the CDS prices in the 12-month time span is not ahead of the dynamics of the government bond's yield). A higher percentage in the result indicates that the hypothesis is confirmed, so that we did not find any preceding of the dynamic in CDS prices to government bond's yield growth rates. In the second equation the hypothesis is that there is no Granger causality between the growth rates of the bond's yield and the growth rates of CDS prices for given country while taking into account a 12-month span. It means that changing the dynamics of the government bond's yield does not precede the CDS price dynamics. The interpretation of the results is similar to the case of the first equation (we are testing the assumption that the government bond's yield dynamics is not ahead of the dynamics in the CDS prices).

\section{REFERENCES}

Ang A., Longstaff F.A. (2012). Systemic Sovereign Credit Risk: Lessons From the U.S. and Europe. NBER Working Paper. http://www.nber.org/papers/w16982. pp. 1-38.

Duffie, D. (1999). Credit Swap Valuation. Financial Analysts Journal. vol.55, no.01, pp. 73-78, http:// dx.doi.org/10.2469/faj.v55.n1.2243

Fontana A., Scheicher M. (2010). An Analysis of the Euro Area Sovereign CDS and Their Relation with Government Bonds. ECB Working paper. No. 1271, December 2010. pp. 1-44.

Granger C. W. J. (1969). Investigating Causal Relations by Econometric Models and Cross-spectral Methods. Econometrica 37 (3), pp. 424-438. 
Li N., Huang A. Y. (2011). Price Discovery between Sovereign Credit Default Swaps and Bond Yield Spreads of Emerging Markets. Journal of Emerging Market Finance. vol. 10, No.2, p. 197225, http://dx.doi.org/10.1177/097265271101000203

Murdock C. W. (2013). Credit Default Swaps: Dubious Instruments. Harvard Business Law Review Online, vol. 3, pp. 133-141.

Stulz R. M. (2010). Credit Default Swaps and the Credit Crisis. Journal of Economic Perspectives. vol. 24, no.1, pp. 73-92, http://dx.doi.org/10.1257/jep.24.1.73 .

\section{DATA SOURCES}

Our analysis was performed on the data from the United Kingdom, Russia, Germany and Slovenia. For these four countries and for the period from January 2009 to December 2012 we collected data from the following sources:

- Trading Economics, New York City (http://www.tradingeconomics.com/) for the yield on the 10-year benchmark government bonds, unemployment rate, interest rates of central banks to overnight credits, consumer price index, stock market index, the percentage of government debt-to-GDP;

- Sovereign Rating And Country T \& C Assessment Histories (April 3, 2013), Standard \& Poor's, (http://www.standardandpoors.com/ratings/sovresearch/en/eu) for the credit rating of bonds edited by the governments of the analyzed countries;

- Database Bloomberg (http://www.bloomberg.com/professional/) for the CDS prices.

The data used in our analysis are published on a daily level for each of the government bond's yields, the CDS prices, Central Bank interest rates, stock market index and credit rating. Depending on the needs of our analysis, we calculated them to the monthly averages. Credit ratings were converted into numerical series where the AAA (stable), the highest rating for a range of $\mathrm{S} \& \mathrm{P}$, numbered with 67, AAA (Watching the negatives) is numbered with a 66 , etc. Consumer price index and the data about unemployment rate are published on a monthly basis. All series available on daily or monthly basis have been seasonally adjusted. The data about government debt-to-GDP are published on an annual basis. These data have been distributed on a monthly level.

\section{NOTES}

${ }^{1}$ CDS was first introduced in 1994. EBRD issued it to insure J.P. Morgan's credit given to the petroleum company Exxon. This first CDS was so bought by J.P. Morgan. In this way the bank reduced the need for capital reserves.

${ }^{2}$ The fact that the obligation in the relationship, established with the bond, wasn't fulfilled is called a "credit event", and it is specifically defined in the contract that establishes the CDS. This definition can mean the bankruptcy of the bond's seller, the restructuring of the credit, common non-payment of the bond's coupons, or even just a decline in the credit rating of the bond's seller (the "reference unit"). 